\title{
Overexpression of p53 protein is a marker of poor prognosis in Mexican women with breast cancer
}

\author{
JISELA DIMAS-GONZÁLEZ ${ }^{1}$, VILMA MALDONADO-LAGUNAS ${ }^{1}$, JOSÉ DÍAZ-CHÁVEZ ${ }^{2}$, \\ MARÍA EUGENIA LÓPEZ-ARELLANO ${ }^{3}$, JOSÉ MUÑOZ-CAMACHO ${ }^{4}$, \\ MARCO ANTONIO TERÁN-PORCAYO ${ }^{4 *}$ and ALFREDO LAGUNAS-MARTÍNEZ ${ }^{5^{*}}$ \\ ${ }^{1}$ National Institute of Genomic Medicine, México City, México; ${ }^{2}$ National Cancer Institute, México City, México; \\ ${ }^{3}$ National Institute for Forestry, Agriculture and Livestock Research, Jiutepec, Morelos, México; \\ ${ }^{4}$ State Cancer Institute 'Dr. Arturo Beltrán Ortega', Acapulco, Guerrero, México; \\ ${ }^{5}$ National Institute of Public Health, Cuernavaca, Morelos, México
}

Received November 30, 2016; Accepted February 2, 2017

DOI: 10.3892/or.2017.5553

\begin{abstract}
Breast cancer (BC) is a disease with different clinical, histological and molecular characteristics, frequently presenting mutated tumour-suppressing genes and oncogenes. P53 is a known tumour suppressor that is often mutated in BC; several mutations in p53 inhibit its role as a transcriptional repressor of several oncogenes. Topoisomerase $2 \alpha$ (TOP $2 \alpha)$ is a gene target of $\mathrm{p} 53$, and it is also a known target for anthracyclines. The aim of the present study, was to analyse the genetic alterations of $p 53$ and TOP $2 \alpha$ genes and their levels of protein expression, as well as their association with survival in Mexican women with BC. A total of 102 biopsies were collected (tumour and adjacent tissues) from patients with BC. To identify point mutations and deletions in the $p 53$ gene, the Sanger sequencing method was carried out. Deletions or amplifications for TOP $2 \alpha$ gene were determined using quantitative polymerase chain reaction (qPCR). In addition, the expression of the TOP $2 \alpha$ and p53 proteins was evaluated by western blotting. Furthermore, p53 protein expression was analysed by proximity ligation assay (PLA)-qPCR. Only $28.5 \%$ of the patients were found to have triple-negative breast cancer (TNBC); the average age at the time of diagnosis of these patients was 50 years, and Scarff-Bloom-Richardson (SBR) histological grade III $(\mathrm{p}=0.0089)$. No differences in point mutations or deletions in $p 53$, and deletions or amplifications as well as protein
\end{abstract}

Correspondence to: Dr Marco Antonio Terán-Porcayo, State Cancer Institute 'Dr. Arturo Beltrán Ortega', Acapulco, Guerrero 39670, México

E-mail: teranporcayo@yahoo.com.mx

M.Sc. Alfredo Lagunas-Martínez, National Institute of Public Health, Cuernavaca, Morelos 62100, México

E-mail: alagunas@insp.mx

*Contributed equally

Key words: breast cancer, p53, TOP $2 \alpha$, TNBC, amplification, deletion, point mutation expression level of TOP $2 \alpha$ were observed between patients with TNBC and non-TNBC patients. However, patients with TNBC showed p53 protein overexpression as determined by PLA-qPCR and western blotting $(\mathrm{p}<0.0001)$. Furthermore, we found an association between TOP $2 \alpha$ amplification and overexpression of its protein in patients with TNBC $(\mathrm{p}<0.0001)$. Concerning $\mathrm{p} 53$, overexpression resulted in a lower survival in patients with $\mathrm{BC}$.

\section{Introduction}

Breast cancer (BC) is a complex and biologically heterogeneous disease, presenting diverse histopathological, clinical and molecular characteristics whose importance must be highlighted when determining its prognosis and treatment outcome. Through immunochemistry, BC is classified as hormone receptor $\left(\mathrm{ER}^{+}, \mathrm{PR}^{+}\right)$-positive, human epidermal growth factor receptor-2 (HER2 $\left.{ }^{+}\right)$-positive and triple-negative $\left(\mathrm{ER}^{-}, \mathrm{PR}^{-}\right.$and HER2-). Approximately $21-27 \%$ of BC tumours possess a mutated p53 gene (1-4).

P53 plays an important role in cell growth arrest, cell death, DNA repair, invasion and metastasis (5). P53 is a tumour suppressor gene whose protein possesses three domains: trans-activating, DNA binding and oligomerization (6). To date, 4,250 p53 gene mutations have been reported in BC tumours; $\sim 90 \%$ of these mutations are found within the DNA binding domain of p53, and these are associated with worse prognosis and poor response to anthracycline treatment [http://wwwp53.iarc.fr/] (1,7). Previous studies have demonstrated that p53 mutants favour cancer development; e.g., p53 ${ }^{w t}$ acts as a transcriptional repressor of the TOP $2 \alpha$ gene. However, p53 mutants fail to inhibit the expression of TOP $2 \alpha$, thus, promoting the carcinogenic process $(8,9)$. Overexpression of the topoisomerase $2 \alpha$ (TOP $2 \alpha$ ) protein is considered a predictive factor with respect to anthracycline sensitivity, whereas its deletion status is associated with increased resistance to the same drug (10-13). Conversely, underexpression of the TOP $2 \alpha$ protein is considered to be a good prognosis factor $(14,15)$.

Despite its potential usefulness through its utilization as a predictive and prognostic factor for $\mathrm{p} 53$, and TOP $2 \alpha$ is 
inconsistent in several studies. Unfortunately, in Mexican women with BC, these markers not have been studied. In the present study population, we found that p53 protein overexpression could be considered a factor for poor prognosis in Mexican women with BC.

\section{Materials and methods}

Patients. A total of 102 biopsies were collected de novo (adjacent and tumour tissues) from patients with BC between September 2011 and December 2012 at the Instituto Estatal de Cancerología (IECan) Dr. Arturo Beltrán Ortega, a Tertiary-Level Hospital (Acapulco, Guerrero, Mexico). Inclusion criteria were the following: patients who voluntarily accepted to be part of the study and who signed an informed consent letter; patients residing in the state of Guerrero; patients of any age at the time of diagnosis of invasive ductal carcinoma (range 31-85 years); clinical stage I, II and III, patients not currently under neoadjuvant treatment, and diagnosis of BC confirmed by the hospital's pathology department. Medical records were checked thoroughly to obtain the patients' clinicpathological and gynaecological characteristics. The exclusion criteria were as follows: presence of cancer antecedents, recurrence of cancer and/or pregnancy. The elimination criteria were as follows: insufficient biopsy material and incomplete clinical history. The project was evaluated and approved by the IECan Ethics and Research Committee.

Classification of genetic alterations. We investigated the genetic alterations of $p 53$ and TOP $2 \alpha$, which were classified as: small-scale mutations (point mutations and deletions) for p53 gene and large-scale mutations (amplifications or deletions) for $T O P 2 \alpha$ gene.

Genomic DNA extraction. Genomic DNA was extracted from breast tissue biopsies (adjacent and tumour tissues) using the DNeasy Blood \& Tissue kit (Qiagen GmbH, Hilden, Germany) according to the manufacturer's instructions. The genomic DNA obtained was quantified, and its integrity was verified by GAPDH end-point PCR.

Protein extraction. Total protein was extracted from breast tissue biopsies (adjacent and tumour tissues) using an Ambion PARIS kit (Applied Biosystems, Carlsbad, CA, USA) according to the manufacturer's instructions. The proteins were quantified using a Pierce BCA protein assay kit (Thermo Fisher Scientific, Rockford, IL USA), and their integrity was verified by resolving the proteins in $8 \%$ sodium dodecyl sulphate-polyacrylamide gel electrophoresis (SDS-PAGE) and Coomassie staining.

End-point PCR and sequencing. To amplify the DNA binding domain of p53 (exons 5-8), two sets of primers were designed using Primer Express ver. 3.0 software (Applied Biosystems, Foster City, CA, USA). One set of primers amplifies a 459 bp fragment from exons 5-6 (F, 5'-TTCCTCTTCCTACAGTAC-3' and R, 5'-AGTTGCAAACCAGACCTCA-3'); the second set amplifies a 510-bp fragment from exons 7-8 (F,5'-GTGTTATCT CCTAGGTTG-3' and R, 5'-TCCTCCACCGCTTCTTGT-3'). PCR products were purified using a QIAquick PCR Purification kit (Qiagen $\mathrm{GmbH}$ ) according to the manufacturer's instructions. The amplicons obtained were quantified and sequenced in a Genetic Analyzer 3130 (Applied Biosystems). The sequences were analysed using MEGA6 software.

TOP $2 \alpha$ copy number evaluation (amplification and deletion) through qPCR. Copy number of the TOP $2 \alpha$ gene were analysed by performing duplex reactions in triplicate using $20 \mathrm{ng}$ of genomic DNA (obtained from adjacent or tumour tissues), a TOP $2 \alpha$ TaqMan Copy Number Assay probe labelled with FAM, a RNase $P$ TaqMan Copy Number Reference probe labelled with VIC, and TaqMan Genotyping Master Mix (all from Applied Biosystems) according to the manufacturer's instructions. The $\mathrm{Ct}$ values obtained were analysed using CopyCaller ver. 2.0 software (Applied Biosystems). The method was validated by performing standard curves generated by serial dilutions of the genomic DNA (1,000-0.1 ng) in triplicate. As a diploid copy number control, genomic DNA was extracted from pooled peripheral-blood samples of healthy women $(n=5)$. As a positive amplification control, genomic DNA from the breast-cancer cell line SKBR3 was utilized.

Proximity ligation assay and $q P C R(P L A-q P C R)$. To perform the proximity ligation assay (PLA), $200 \mathrm{nM}$ aliquots of the probes 3' Prox-Oligo and 5' Prox-Oligo (Applied Biosystems) were separately incubated with $200 \mathrm{nM}$ biotinylated polyclonal p53 antibody (R\&D Systems, Minneapolis, MN, USA) for $60 \mathrm{~min}$ at room temperature. Afterward, Assay Probe Storage Buffer was added and incubated for $30 \mathrm{~min}$ at room temperature. One microgram of total protein extract (from adjacent or tumour tissue) was incubated overnight with $250 \mathrm{pmol}$ of the probes $3^{\prime}$ and $5^{\prime}$ Prox-Oligo antibody conjugated at $4^{\circ} \mathrm{C}$. Next, the ligation mix was added to each tissue lysate containing total protein. The ligation reaction was incubated for $10 \mathrm{~min}$ at $37^{\circ} \mathrm{C}$ and after this, at $4^{\circ} \mathrm{C}$ for an additional $10 \mathrm{~min}$. Finally, the reaction mix was supplemented with protease, incubated for $10 \mathrm{~min}$ at $37^{\circ} \mathrm{C}$, inactivated at $95^{\circ} \mathrm{C}$ for $5 \mathrm{~min}$ and maintained overnight at $4^{\circ} \mathrm{C}$ (Applied Biosystems). The qPCR assay was performed using the TaqMan ${ }^{\circledR}$ Protein Assays Fast Master Mix (Applied Biosystems) and $9 \mu \mathrm{l}$ of the protein lysate obtained from the PLA assay. PCR conditions were as follows: 2 min at $95^{\circ} \mathrm{C}$ and 40 cycles of $15 \mathrm{sec}$ at $95^{\circ} \mathrm{C}$ and $1 \mathrm{~min}$ at $60^{\circ} \mathrm{C}$. $\mathrm{Ct}$ values were imported into Protein Assist ${ }^{\mathrm{TM}}$ software v1.0 (Applied Biosystems), in which the relative quantification analysis was performed. Prior to analysis of the protein lysates, a dynamic range was elaborated, and the reaction efficiency was verified with a serial dilution standard curve in triplicate. The cut-off limit for the relative expression of the p53 protein was $<1.0$ for underexpression and $>1.0$ for overexpression.

Western blotting. Thirty micrograms of total protein (from adjacent and tumour tissues) were resolved in a $10 \%$ SDS-PAGE gel. The proteins were transferred onto a nitrocellulose membrane (GE Healthcare, Buckinghamshire, UK) and blocked with $5 \%$ non-fat milk for $1 \mathrm{~h}$ at room temperature. The membrane was then incubated overnight with polyclonal rabbit anti-human TOP $2 \alpha$ antibody (Abcam, Cambridge, UK) or monoclonal mouse anti-human p53-HRP antibody (Santa Cruz Biotechnology, Inc., Dallas, TX, USA) at $4^{\circ} \mathrm{C}$. The membranes were washed three times with TBS/Tween-20 $0.1 \%$. Additionally, the membrane employed for TOP $2 \alpha$ detec- 
tion was incubated for an additional $1 \mathrm{~h}$ with a secondary horseradish peroxidase (HRP)-conjugated anti-rabbit antibody (Sigma Chemical Co., St. Louis, MO, USA). Protein detection was performed using the reagent SuperSignal West Pico Chemiluminescent Substrate (Thermo Scientific, Rockford, IL, USA), and the chemiluminescent signal was detected using a VersaDoc Imaging System (Bio-Rad, Hercules, CA, USA). The monoclonal mouse anti-human $\beta$-tubulin antibody (Sigma Chemical Co.) was employed as a loading control. The densitometric analysis was performed using ImageJ software. TOP $2 \alpha$ protein expression was normalized against the loading control ( $\beta$-tubulin); then, TOP $2 \alpha$ expression in the tumour tissue was normalized against the adjacent tissue. P53 protein expression was analysed in all samples (adjacent and tumour tissues), but detection was only identified in the tumour samples. In this case, the p53 protein was normalized only against the loading control ( $\beta$-tubulin), since the half-life of the p53 protein is short, and it was not possible to detect its expression in the adjacent tissue.

Immunohistochemistry. To determine the presence of the estrogen, progesterone and HER2 receptors, 5- $\mu$ m-thick sections were obtained from paraffin-embedded tissue. The primary antibodies used were the monoclonal mouse anti-human estrogen receptor clone 1D5 (Biocare Medical, Concord, CA, USA), the monoclonal mouse anti-human progesterone receptor clone $\operatorname{PgR} 636$, and the polyclonal rabbit anti-human c-erbB-2 oncoprotein (both from Dako, Carpinteria, CA, USA). The detection system utilized was the mouse/rabbit UnoVue HRP/DAB detection system (Diagnostic BioSystems, Pleasanton, CA, USA). For each biopsy, a previously selected positive control was also analysed by the pathologist as an internal quality control. Data interpretation was performed using the Allred system, and for HER2, cells were defined as $3+$ positive, $2+$ intermediate and $0-1+$ negative. HER2 biopsies with intermediate values $(2+)$ were outsourced to an immunohistochemistry and molecular pathology laboratory (INMUNO Q, México, D.F.) for validation by means of a Silver In Situ Hybridization (SISH) assay.

Statistical analysis. Patients were subdivided into two groups: non-TNBC patients, expressing at least one of the receptors (RE, RP or HER2) and TNBC, lacking all of these receptors. To compare clinical and pathological variables, point mutation or deletion in $p 53$ gene, amplification or deletion in TOP $2 \alpha$ gene, and SNPs in $p 53$ gene by groups, we used an $\chi^{2}$ test. Age at the time of diagnosis was compared with a non-linear Gaussian adjustment for accumulated relative frequencies. The relative expression of the TOP $2 \alpha$ and $\mathrm{p} 53$ proteins determined through western blotting and/or PLA-qPCR, were analysed by the multiple Student's t-test. Analysis of variance (ANOVA) was used to compare the relative expression of the p53 and TOP $2 \alpha$ proteins vs. genetic alterations of these genes. In all cases, $\mathrm{p}<0.05$ was considered to be significant.

In addition, a multiple correspondence analysis (MCA) was used (16), which is a descriptive method to determine the relationshipbetween specific groups. MCA uses an $\chi^{2}$-calculated distance to assess the association between clinicopathological variables (clinical groups, SBR histological grade), large-scale mutations in the TOP $2 \alpha$ (amplification or deletion) and small- scale mutations in the $p 53$ (point mutation or deletion) genes, and the relative expression of the TOP $2 \alpha$ and p53 proteins. Based on these distances, the correspondence analysis registers two sets of combinations, generating a score calculated for each group. The first combination (dimension 1) defined a scale of variation that allowed the highest discrimination between groups. The second combination (dimension 2) defined the maximum dispersion between uncorrelated groups and the relative expression of the TOP $2 \alpha$ and p53 proteins. To compare relative expression values of the TOP $2 \alpha$ and $\mathrm{p} 53$ proteins, the results were divided in percentiles starting from 33 and $66 \%$. Three sets of each variable were generated: underexpression $<33 \%$ (<0.9), basal expression (normal) 33-66\% (0.9-1.1) and overexpression $>66 \%$ (>1.1) (16).

Finally, survival curves were determined using the KaplanMeier method and verified by a log-rank test (Mantel-Cox) with a follow-up period of 26 months, as patients continue in follow-up on the present study.

\section{Results}

Clinicopathological features of patients with BC. The analysed population consisted of 102 patients with BC, of whom $71.5 \%$ were diagnosed as non-TNBC and $28.5 \%$ were diagnosed as TNBC (Fig. 1A). The age of TNBC patients at time of diagnosis was estimated as $50.2( \pm 11.3)$ years of age on average, whereas the age of non-TNBC patients was estimated as $55.01( \pm 10.3)$ years of age on average. The accumulated relative frequencies of both groups were significant (p<0.0001) (Fig. 1B). TNBC patients exhibited $82.7 \%$ of SBR histological grade III ( $p=0.0089)$ (Fig. 1C) and $37.9 \%$ recurrence $(\mathrm{p}=0.017)$ (Fig. 1D) when compared with non-TNBC patients (50.6 and $15.1 \%$, respectively).

Furthermore, TNBC patients presented only stages II and III $(p=0.539)$ (Fig. 1E), larger tumour size $(p=0.393)($ Fig. 1F), and a higher frequency of positive lymph nodes in N2 status $(p=0.935)$ (Fig. 1G); we did not observe significant differences between non-TNBC and TNBC patients.

Genetic alterations of the 553 gene and 53 protein expression. Since the tumour suppressor gene $p 53$ is mutated in $\sim 50 \%$ of all types of cancer, we evaluated small-scale mutations (point mutations, deletions) in this gene through DNA sequencing of exons $5-8$, which are frequently mutated. We found genetic alterations in the $p 53$ gene in $27.5 \%$ of patients with $\mathrm{BC}$, of which $9.8 \%$ were point mutations (missense) and $17.7 \%$ were specific deletions in exons 5-6 (Table I).

The majority of PCR amplicons spanning exons 5-6 exhibited a similar migration pattern by electrophoresis (459 bp, expected molecular weight); however, in some cases, we observed an amplicon of $395 \mathrm{bp}$, suggesting that the latter represents an allele carrying a deletion (Fig. 2A). We were able to identify an $\sim 64$ bp deletion corresponding to codons 191-216 (exon 6) (Fig. 2B).

In addition, it was through DNA sequencing that we identified single nucleotide polymorphisms (SNPs) rs1294778 and rs12951053 localized inside intron 7 of $p 53$, both of which had a frequency of $25.5 \%$ in the study population (Table I). Both SNPs (homozygotes or heterozygotes, according to the case) were identified in the same patients. No significant differences 
A
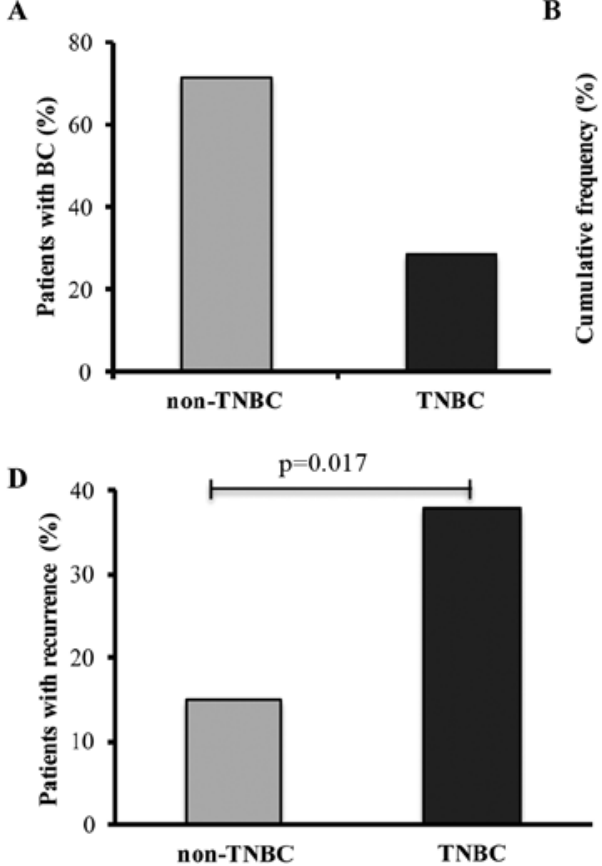

$\mathbf{F}$

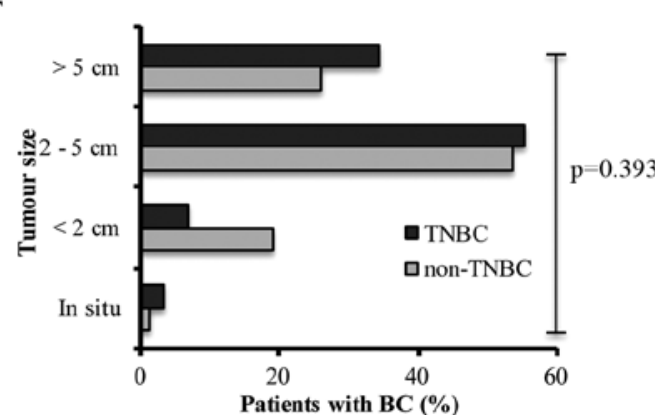

B

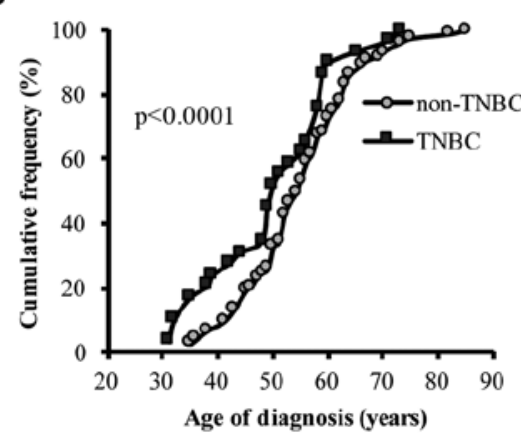

C

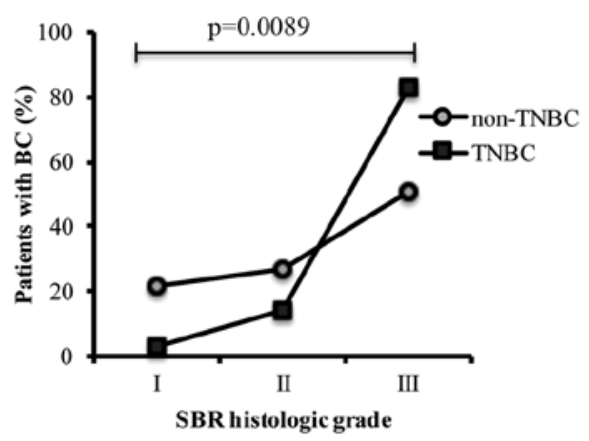

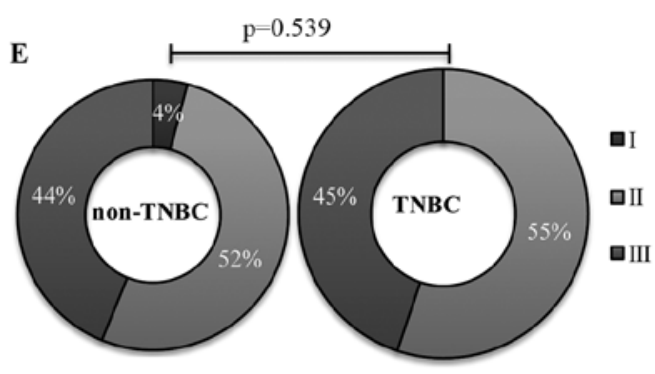

G

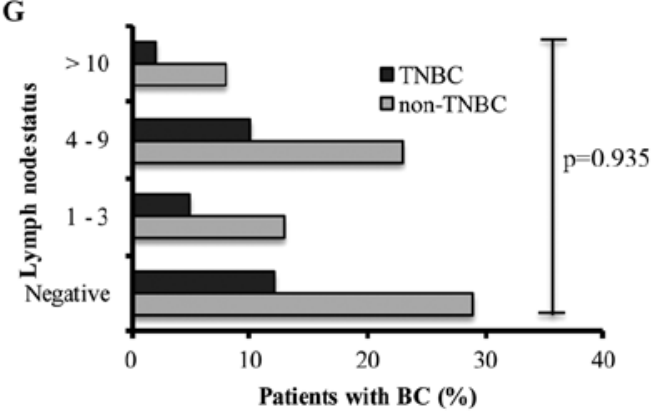

Figure 1. Clinical and pathological characteristics of the patients with breast cancer. (A) Clinical groups of non-TNBC and TNBC patients. (B) Accumulated frequency of age at time of diagnosis per group. (C) Scarff-Bloom-Richardson (SBR) histological grade. (D) Recurrence. (E) Clinical stage. (F) Tumour size and $(\mathrm{G})$ lymph node status. $\mathrm{p} \leq 0.05$ was considered significant. TNBC, triple-negative breast cancer.

A

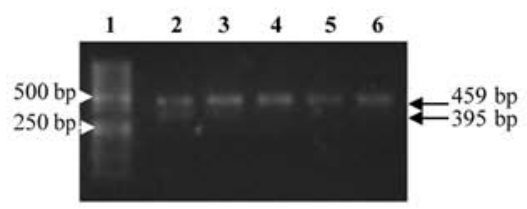

B

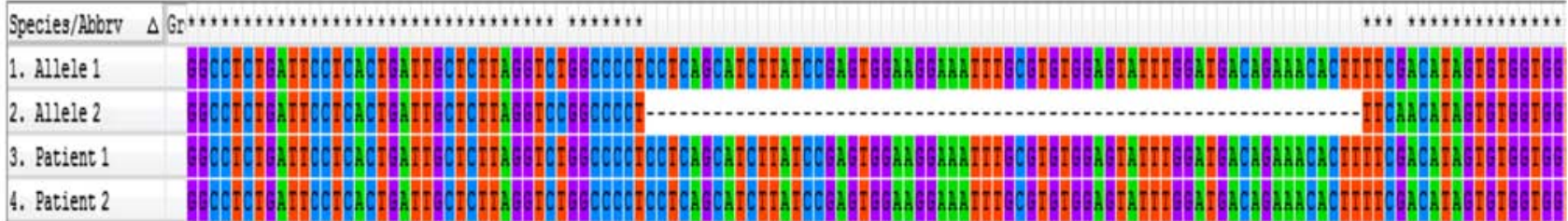

Figure 2. Polymerase chain reaction (PCR) and sequence of exons 5-6 of the $p 53$ gene. (A) PCR products of exons 5-6: lane 1, DNA molecular weight marker (DMWM); lane 2-3, patients with deletion in one allele; and lanes 4-6, patients without point mutation or deletion. (B) Alignment of the sequences of exons 5-6 of two patients without deletion and alleles with or without deletion of one patient.

were found between TNBC and non-TNBC patients regarding either deletions or mutations ( $\mathrm{p}=0.0655$ ) (Fig. 3A), and SNPs (rs1294778 and rs12951053) (data not shown) identified for $p 53$.
To determine whether point mutations or deletions found in the $p 53$ gene compromise its protein expression, all of the $\mathrm{BC}$ samples were analysed by western blotting. A representative 
Table I. TP53 and TOP2 $\alpha$ status in patients with BC.

\begin{tabular}{|c|c|c|c|}
\hline Gene status & Position & Characteristics & $\begin{array}{c}\text { Frequency } \\
(\mathrm{n}=102)\end{array}$ \\
\hline Wild-type TP53 gene & & & $72.5 \%$ \\
\hline Alteration of the TP53 gene & & & $27.5 \%$ \\
\hline \multicolumn{4}{|c|}{$\begin{array}{l}\text { Subcategorization of the alteration } \\
\text { of the TP53 gene }\end{array}$} \\
\hline Missense mutation & Exons 5-8 & Protein change by one amino acid or truncated & $9.8 \%$ \\
\hline Deletion & Exons 5-6 & Truncating mutation & $17.7 \%$ \\
\hline \multicolumn{4}{|l|}{ SNPs in the TP53 gene } \\
\hline SNP rs 12947788 & Intron 7 & No change in expression of the protein & $25.5 \%$ \\
\hline SNP rs 12951053 & Intron 7 & No change in expression of the protein & $25.5 \%$ \\
\hline Wild-type $T O P 2 \alpha$ gene & & & $67.6 \%$ \\
\hline Alteration of the $T O P 2 \alpha$ gene & & & $32.4 \%$ \\
\hline \multicolumn{4}{|c|}{$\begin{array}{l}\text { Subcategorization of the alteration } \\
\text { of the TOP } 2 \alpha \text { gene }\end{array}$} \\
\hline Deletion & Gene & No protein expression & $20.6 \%$ \\
\hline Amplification & Gene & $\begin{array}{l}\text { Modified protein expression } \\
\text { (underexpression, overexpression) }\end{array}$ & $11.8 \%$ \\
\hline
\end{tabular}

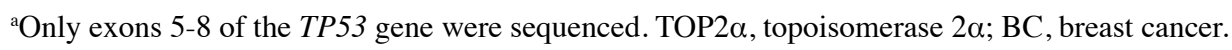

image of western blotting of the p53 protein is shown in Fig. 3B. When comparing p53 protein expression levels, we observed a statistically significant average of $0.78( \pm 1.63)$ in the TNBC group $(\mathrm{p}=0.005)$ compared with the non-TNBC group (mean, $0.10 \pm 0.43$ ) (Fig. 3C). We normalized the relative expression of the $\mathrm{p} 53$ protein using the loading control $\beta$-tubulin since normal adjacent tissue lack or present low levels of p53 protein. In contrast, p53 mutant proteins have a characteristically long half-life $(4,17)$.

Next, we validated the results of p53 protein expression using PLA-qPCR, a technique more sensitive than western blotting. We found an average p53 protein expression of $1.83( \pm 1.75)$ and $0.62( \pm 0.65)$ in the TNBC and non-TNBC groups, respectively. The difference among these results was statistically significant ( $<<0.0001)$ (Fig. 3C).

Furthermore, we analysed an association among $p 53$ gene alterations with p53 protein expression. We observed that patients carrying deletions in the $p 53$ gene present underexpression or null expression of the p53 protein, as shown by PLA-qPCR or western blotting analysis, respectively (Fig. 3D). Patients with different mutations in the $p 53$ gene present either underexpression or overexpression of the p53 protein, with both situations observed through western blotting and PLA-qPCR (Fig. 3D). In some cases, patients showing no alterations (point mutations or deletions) in exons 5-8 also showed expression of the p53 protein. This may be due to mutations localized in the unexamined regions of the $p 53$ gene (Fig. 3D).

Genetic alterations of the TOP $2 \alpha$ gene and protein expression. Similar to $\mathrm{p} 53, \mathrm{TOP} 2 \alpha$ is altered in cancer. Thus, we evaluated large-scale mutations (amplifications or deletions) for the TOP $2 \alpha$ gene by qPCR. We found that $32.4 \%$ of all patients analysed showed genetic alterations in this gene, among whom $20.6 \%$ presented deletions and $11.8 \%$ showed amplifications of the TOP $2 \alpha$ gene (Table I). However, there were no significant differences in either TOP $2 \alpha$ gene deletions or amplifications between the TNBC and non-TNBC patient groups $(p=0.4508)$ (Fig. 4A). To determine whether such amplifications or deletions exert any effect on TOP $2 \alpha$ protein expression, the BC samples were evaluated by western blot analysis (adjacent and tumour tissues). We observed that the average TOP $2 \alpha$ protein expression was $1.36( \pm 2.95)$ in TNBC and $1.40( \pm 3.79)$ in the non-TNBC group. The patients showed similar expression levels of TOP $2 \alpha$ protein between the groups without a significant difference $(\mathrm{p}=0.960)$ (Fig. 4B). We show a representative image of the western blotting of proteins obtained of two patients with BC for TOP $2 \alpha$ protein. $\beta$-tubulin was used as the loading control (Fig. 4C). When comparing the amplifications or deletions and protein expression of TOP $2 \alpha$, we observed a higher expression of the TOP $2 \alpha$ protein in patients lacking any TOP $2 \alpha$ genetic alterations and decreased TOP $2 \alpha$ protein levels in patients carrying TOP $2 \alpha$ deletions. Individual group evaluations revealed higher TOP $2 \alpha$ protein expression in TNBC patients carrying gene amplifications when compared with non-TNBC patients ( $\mathrm{p}=0.023)$ (Fig. 4D).

Associated characteristics in patients with BC. To determine the association between the clinical and pathological characteristics (clinical group, histological grade) of patients with genetic alterations (previously described) in the TOP $2 \alpha$ and p53 genes and the expression level of proteins, we carried out an MCA. We identified three groups by means of an MCA as follows: the first group of TNBC patients was associated 
A

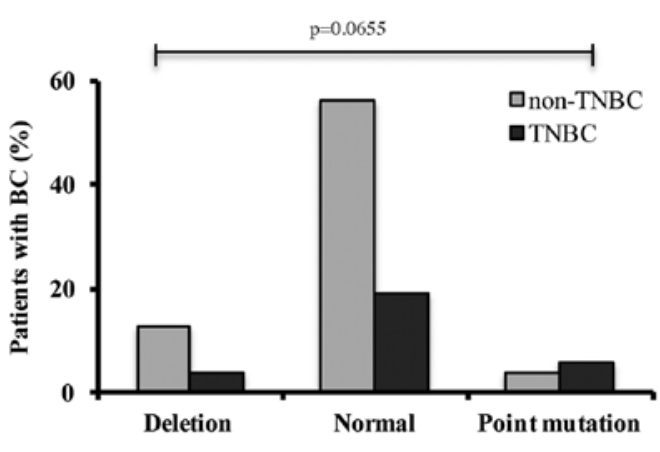

C

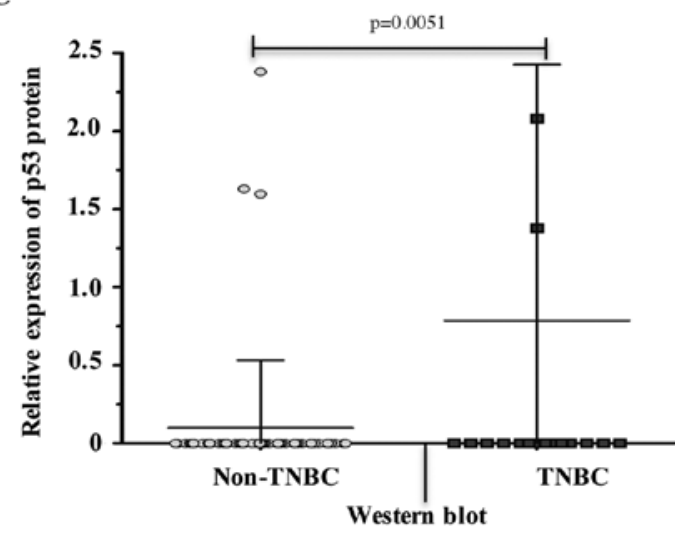

D

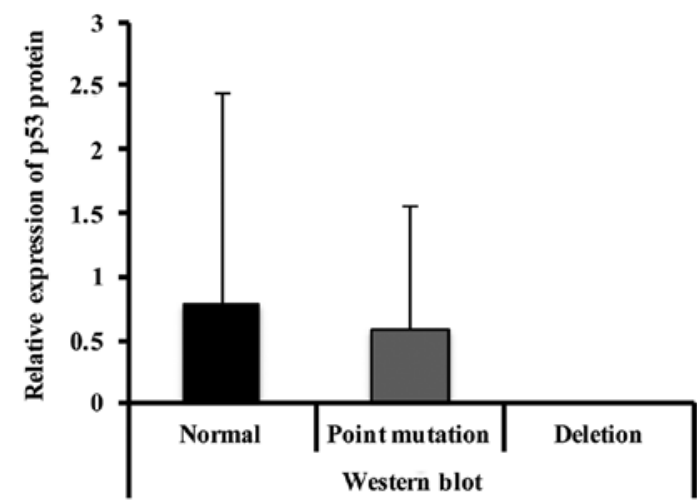

B
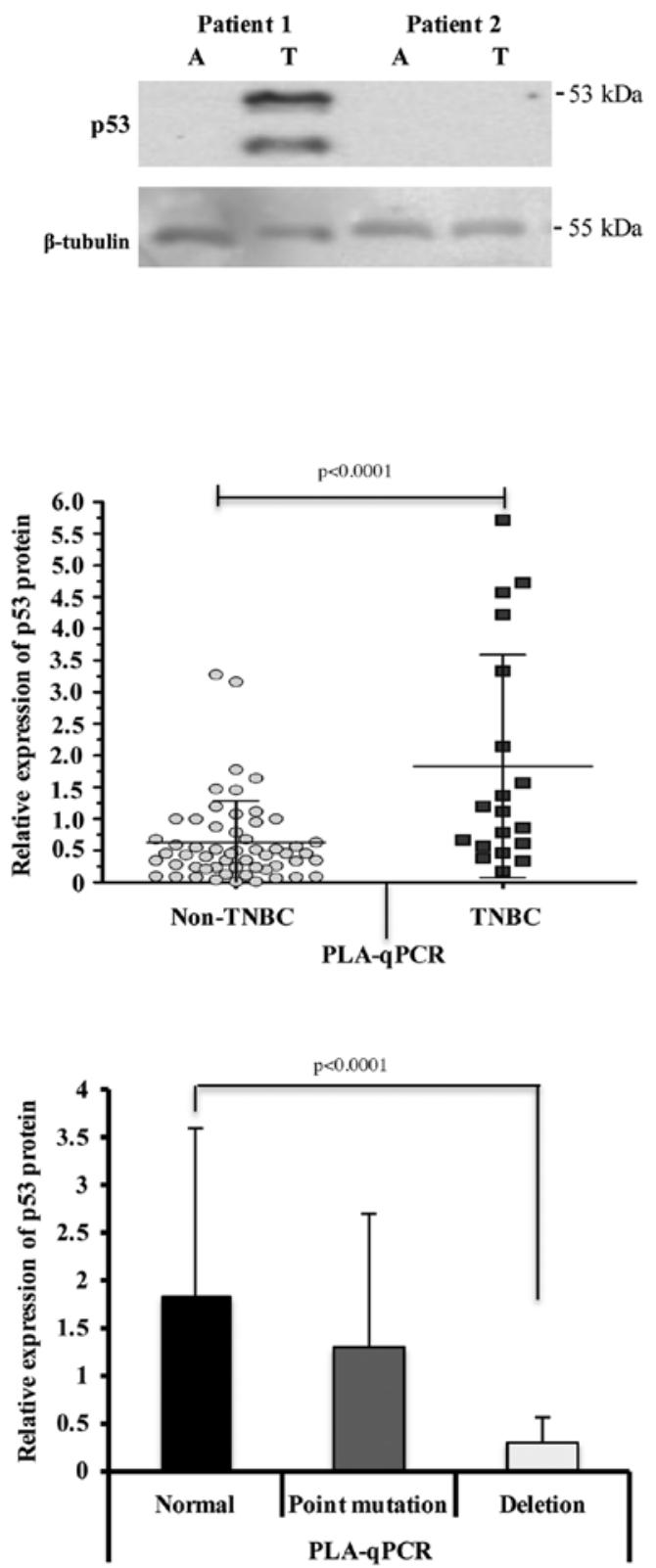

Figure 3. Genetic alterations of the $p 53$ gene and p53 protein expression in patients with breast cancer (BC). (A) Genetic alterations (deletion or point mutation) of the p53 gene. (B) Representative image of the western blotting of p53 and $\beta$-tubulin. A (adjacent tissue); $\mathrm{T}$ (tumour tissue). (C) Relative expression of the p53 protein as measured by proximity ligation assay-quantitative polymerase chain reaction (PLA-qPCR) and western blotting. (D) Comparison between genetic alterations of the $p 53$ gene (x-axis) and protein expression ( $\mathrm{y}$-axis) through western blotting (on the left) and PLA-qPCR (on the right). $\mathrm{p} \leq 0.05 \mathrm{was}$ considered significant; \pm standard deviation (SD).

with a point mutation in the $p 53$ gene and p53 protein overexpression, due to a increase in the p53 protein's half-life. Additionally, we detected the amplification of the TOP $2 \alpha$ gene in this group despite the fact that TOP $2 \alpha$ protein expression was not associated with any clinical group. The second group of non-TNBC patients was associated with a p53 gene deletion, underexpression of the $\mathrm{p} 53$ protein, a non-altered TOP $2 \alpha$ gene (although overexpressed protein), and SBR histological grade II. The third group represented by patients of any group (TNBC or non-TNBC) presented with a TOP $2 \alpha$ gene deletion and a baseline expression level of both the p53 and TOP $2 \alpha$ proteins (Fig. 5).
Survival analysis of patients with $B C$. The follow-up period for patients studied with $\mathrm{BC}$ was set at 26 months, and the patients are undergoing continued follow-up. We observed a general survival of $91.2 \%$ in the study population. In the groups, we observed a 79.3\% survival for the TNBC group and $95.8 \%$ for the non-TNBC group $(\mathrm{p}=0.015)$. In relation to time of survival for the study population, the mean was 25.36 months, with 24.1 months for the TNBC group and 25.8 months for the non-TNBC group ( $\mathrm{p}=0.002)$ (data not shown).

After that, we analysed the prognostic factor of point mutations or deletions in the p53 gene. In patients with $\mathrm{BC}$ that presented a deletion in the $p 53$ gene, the survival was 

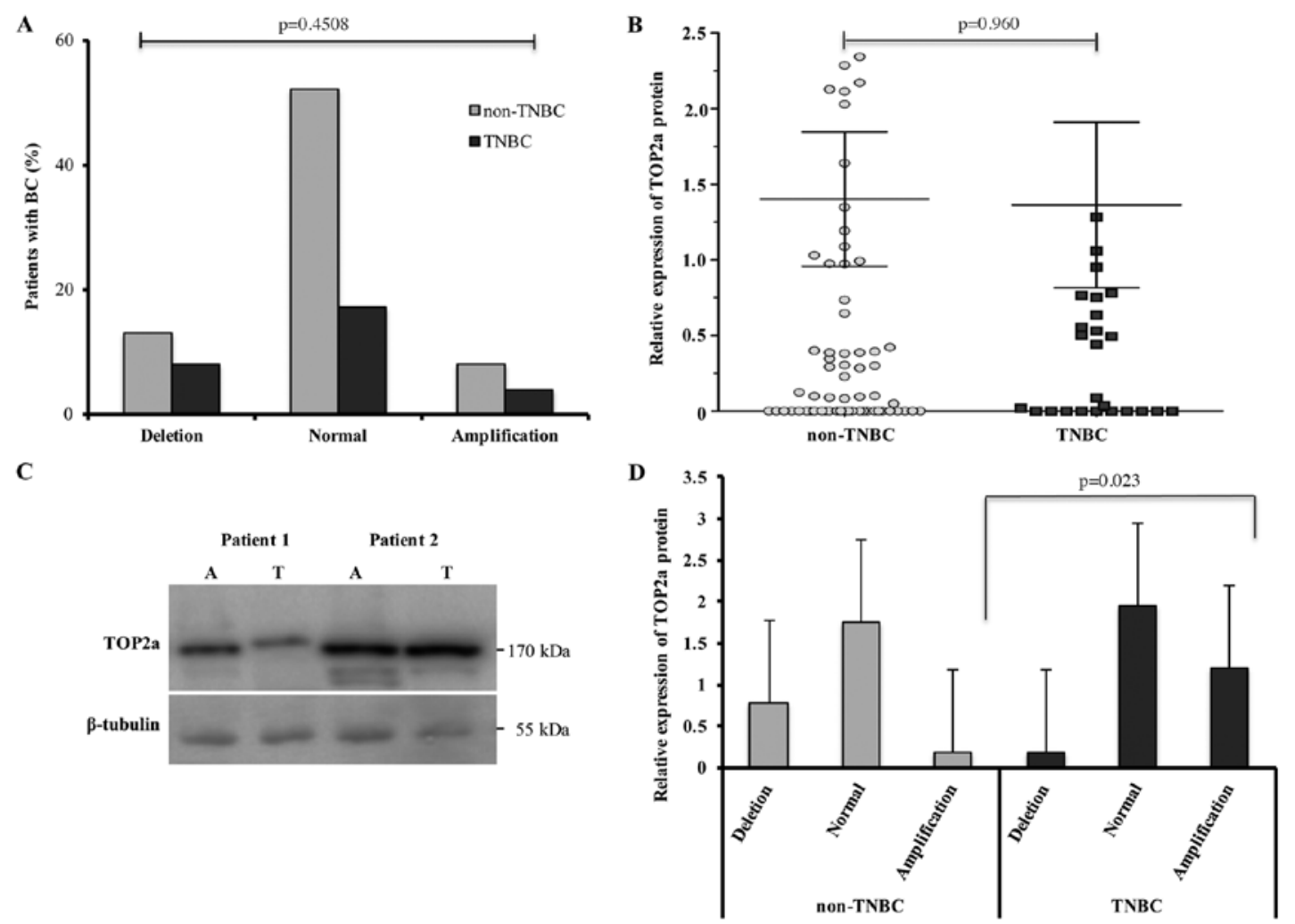

Figure 4. Genetic alterations of the TOP $2 \alpha$ gene and TOP $2 \alpha$ protein expression in patients with breast cancer (BC). (A) Genetic alterations (deletion or amplification) of the TOP $2 \alpha$ gene. (B) Relative expression of the TOP $2 \alpha$ protein by clinical groups. (C) Representative image of the western blotting of TOP2 $\alpha$ proteins obtained from two patients with BC. $\beta$-tubulin was used as the loading control. A (adjacent tissue); T (tumour tissue). (D) Comparison between genetic alterations of the TOP $2 \alpha$ gene (x-axis) and its protein expression (y-axis) through western blotting. $\mathrm{p} \leq 0.05$ was considered significant; \pm standard deviation (SD).

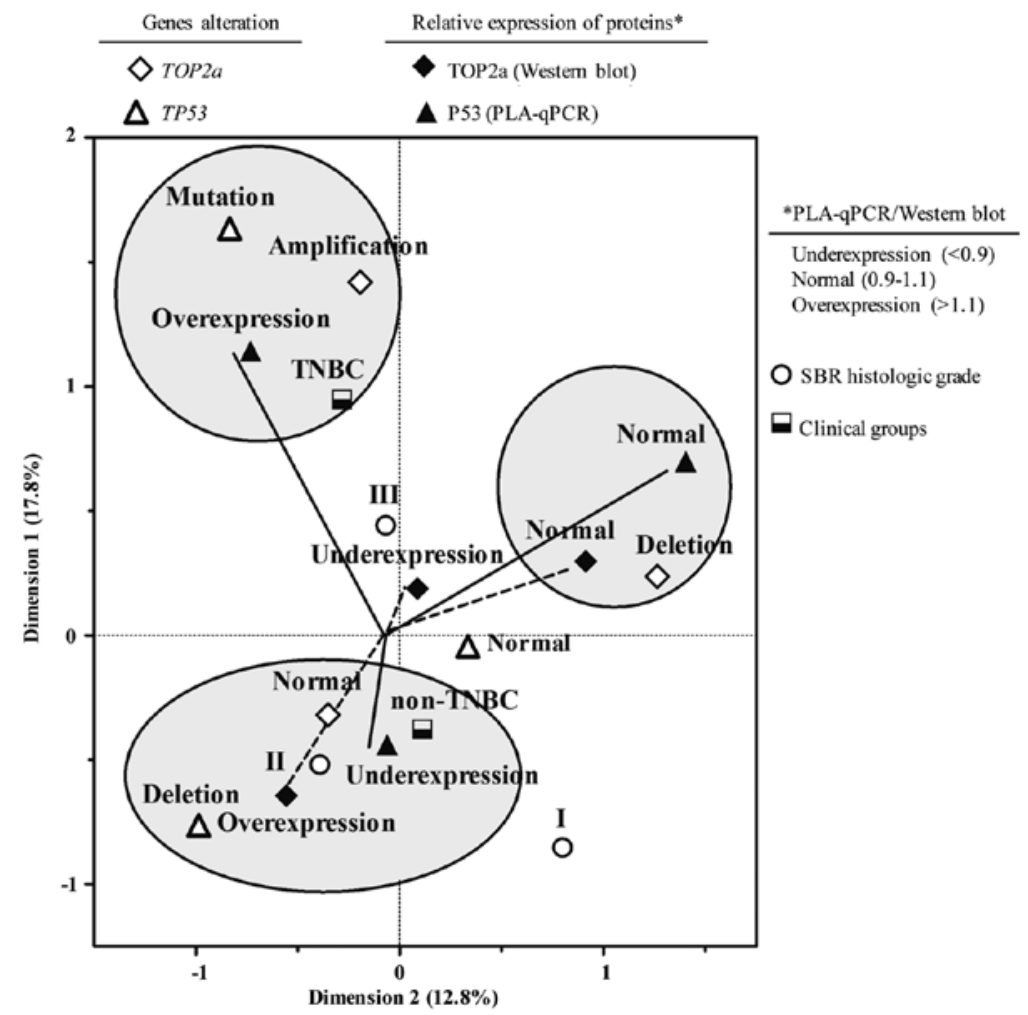

Figure 5. Multiple correspondence analysis (MCA) in patients with breast cancer (BC). In this analysis we observed three groups: in the first group TNBC patients were associated with point mutations in the $p 53$ gene and protein overexpression, as well as gene amplification of TOP2 $\alpha$. The second group was formed with the non-TNBC patients, deletion of the $p 53$ gene and protein underexpression, and overexpression of the TOP $2 \alpha$ protein. The third group was formed with patients of both clinical groups, a basal expression of $\mathrm{p} 53$ and TOP $2 \alpha$ proteins and TOP $2 \alpha$ gene deletion. The sum of dimension 1 and 2 accounted for $30 \%$ of the total variation exhibited by the data. TNBC, triple-negative breast cancer. 
A

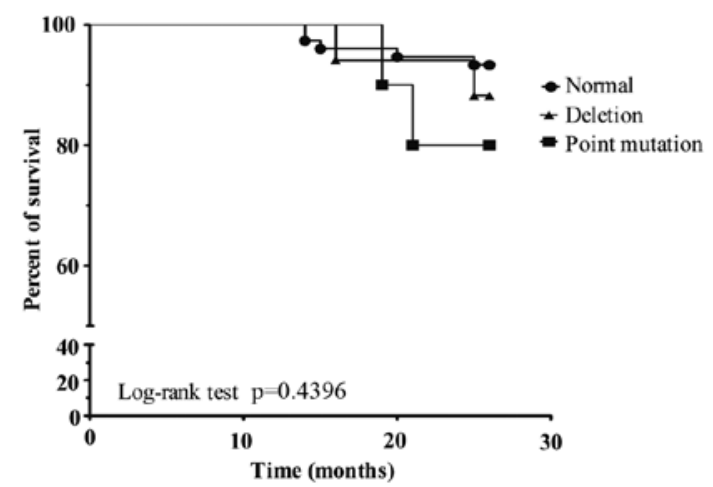

C

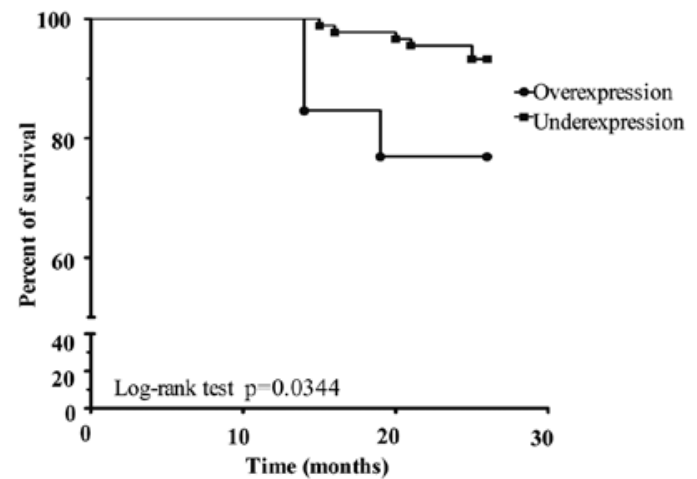

B

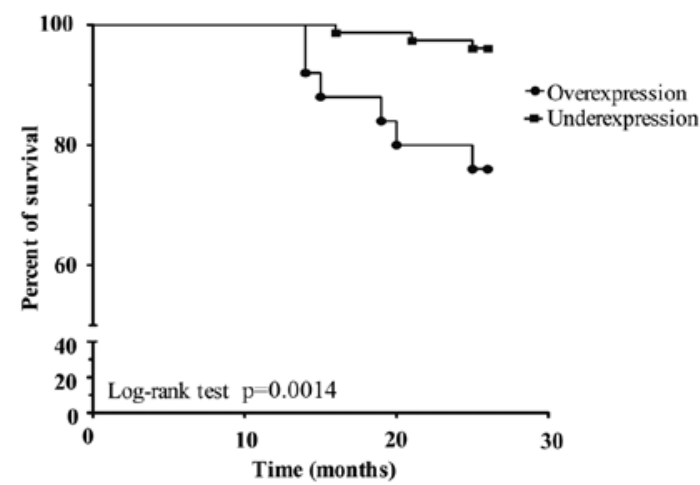

D

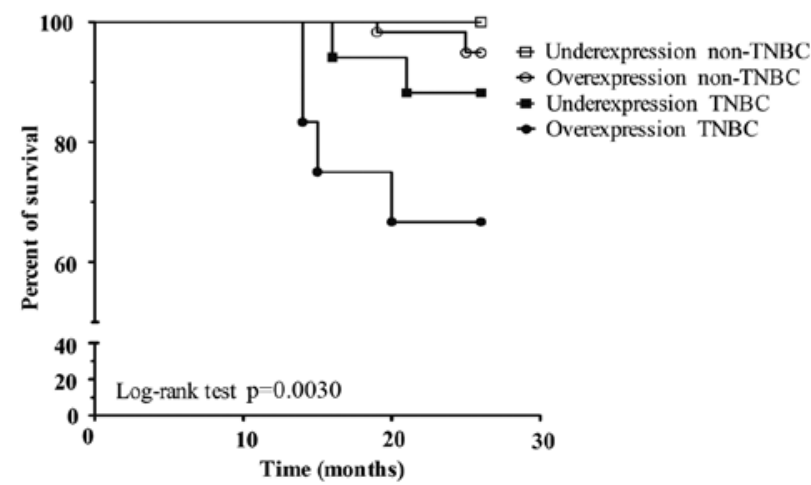

Figure 6. Prognostic value of p53 status. (A) Genetic alterations of the $p 53$ gene (point mutation or deletion). (B) Underexpression and overexpression of the p53 protein by proximity ligation assay-quantitative polymerase chain reaction (PLA-qPCR). (C) Underexpression and overexpression of the p53 protein by western blotting. (D) Underexpression and overexpression of the $\mathrm{p} 53$ protein by clinical group. $\mathrm{p} \leq 0.05$ was considered significant.

A

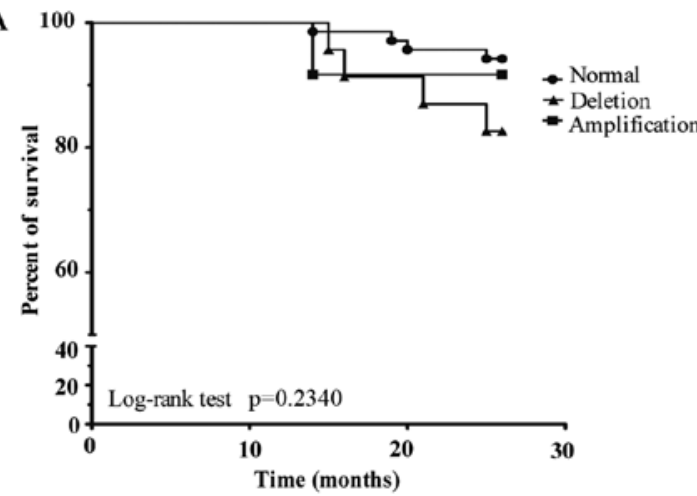

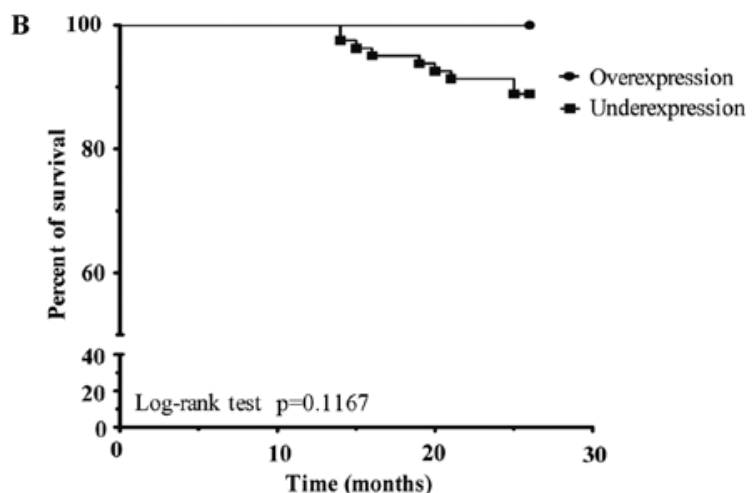

Figure 7. Prognostic value of TOP $2 \alpha$ status. (A) Genetic alterations of the TOP $2 \alpha$ gene (deletion or amplification). (B) Underexpression and overexpression of the TOP $2 \alpha$ protein. $\mathrm{p} \leq 0.05$ was considered significant.

$88.2 \%$; in patients who had a point mutation, the survival was $80 \%$. In neither case was the survival statistically significant $(p=0.4396)$ (Fig. 6A). In contrast, when we analysed p53 protein expression through PLA-qPCR (Fig. 6B) in the same group of patients, we found that p53 overexpression was associated with a lower survival (76\%) compared with p53 underexpression (96\%), suggesting a poor prognosis factor $(\mathrm{p}=0.0014)$. Similarly, using western blotting we found an association between $\mathrm{p} 53$ overexpression and a lower survival (76.9\%, $\mathrm{p}=0.0344$ ) (Fig. 6C). In addition, when we analysed p53 protein expression and its association with a clinical group, we observed that TNBC patients with p53 overexpression presented a lower survival $(\mathrm{p}=0.0030)$ (Fig. 6D).

Finally, we analysed whether amplifications or deletions in the TOP $2 \alpha$ gene are a prognostic factor. To perform this analysis, two groups were generated as follows: i) a group without genetic alterations of the TOP $2 \alpha$ gene (normal) presented with a survival of $94.2 \%$; ii) a group with amplification presented with a survival of $91.6 \%$; and iii) a group with deletion presented with a survival of $82.6 \%(\mathrm{p}=0.2340)$ (Fig. 7A). Although patients with TOP $2 \alpha$ underexpression had a survival of $88.8 \%$, this result was not 
statistically significant ( $\mathrm{p}=0.1167$ ) (Fig. 7B). However, neither TOP $2 \alpha$ amplifications or deletions nor protein expression was a factor for poor prognosis in patients with $\mathrm{BC}$.

\section{Discussion}

We found that overexpression of the $\mathrm{p} 53$ protein was associated with lower survival and could be considered to be a factor for poor prognosis in Mexican women with BC.

In the present study, TNBC patients were characterized as being younger at the time of diagnosis, with SBR histological grade III, and presented recurrence, which have been previously reported $(18,19)$. Our findings agree with past studies performed on Mexican TNBC patients or Hispanic women residing in the US (18-20).

We did not find any correlation between amplifications or deletions and protein expression of TOP $2 \alpha$, as has been previously reported (11). Brase et al solely identified an association in the borderline limit between TOP $2 \alpha$ mRNA and protein levels (11). Similarly, TOP2 $\alpha$ amplifications or deletions and protein expression are not considered to be factors for poor prognosis in the present study population. Our results are in agreement with studies in which these variables were also analysed without finding a difference in prognosis $(15,21)$. Nevertheless, there are other studies where TOP $2 \alpha$ overexpression is considered to be a factor for poor prognosis $(11,14,22)$.

Point mutations (missense) in the $p 53$ gene, localized mainly in the DNA binding domain (exons 5-8), are associated with worse prognosis and are considered to be predictive factors of anthracycline treatment unresponsiveness $(1,7)$. We found genetic alterations (point mutations or deletions) for the $p 53$ gene similar to previously reported frequencies $(3,4,23)$. The alterations most frequently found in the present study were deletions (17\%), despite the fact that point mutations are reported as the most common. Similar to the present study, several studies (in different tumours) also have found $p 53$ gene deletions ranging from 8 to $25 \%$ (24-26). We observed deletions in only one allele, localized in exons 5-6 of $p 53$ gene. One sample was characterized by the deletion of 65 bp in codons 191-216 (exon 6), which to date has not been reported in the tumour mutation database for $p 53$ gene [http://wwwp53.iarc.fr/]. Unfortunately, it was not possible to characterize the deletions detected in all samples due to insufficient sample material. Similar to what has been reported, we found that point mutations were more frequent in TNBC patients $(4,17,27)$. It is known that some $p 53$ point mutations can increase the half-life of the protein, thus favouring its overexpression $(4,17)$. In agreement with these studies, we observed p53 overexpression in TNBC patients. However, we did not find that point mutations or deletions of the $p 53$ gene were associated with survival. We observed that patients with point mutations in the $p 53$ gene have a survival of $<80 \%$, which was not statistically significant $(\mathrm{p}=0.4396)$. It is possible that with a larger sample size, point mutations in the $p 53$ gene may be shown to be a poor prognostic factor. Nevertheless, overexpression of the $\mathrm{p} 53$ protein was significantly associated with a lower survival $(\mathrm{p}=0.0014)$, and we suggest in the present study that it could be a factor for poor prognosis in Mexican patients with BC. This result was observed using both analysis techniques, PLA-qPCR and western blotting. In addition, overexpression of the p53 protein was a worse prognostic indicator for patients with TNCB. Our results coincide with others studies that report the overexpression of $\mathrm{p} 53$ protein is a factor of poor prognosis in $\mathrm{BC}$, and particularly in the TNBC subtype (28-30). Additionally, we identified a high frequency of Mexican patients with TNBC. Other studies, have also reported a high frequency of the TNBC subtype in Mexican patients with BC $(18,20)$. Therefore, in the future the identification of TNBC patients (which on its own is a poor prognosis) who present overexpression of the $\mathrm{p} 53$ protein (as a prognostic biomarker) should be carried out to establish health policies and suggest a treatment more personalized for this group.

In addition, $p 53$ mutations are considered to be predictive factors for unresponsiveness to anthracycline treatment schemes $(7,25,31)$. The overexpression of the TOP $2 \alpha$ protein is also considered to be a predictive factor for anthracycline sensitivity, whereas deletion status is associated with increased resistance to the same drug (10-13). We cannot determine the predictive value of these molecules with the anthracycline scheme since they were not administered with neoadjuvant chemotherapy in the study population. However, it is possible that at the end of five years of follow-up of the patients, we may be able to establish an association between recurrence and genetic alterations, and $\mathrm{p} 53$ and TOP $2 \alpha$ protein expression. We suggest that recurrence is the result of a negative response to the anthracycline scheme since $94.1 \%$ received adjuvant chemotherapy containing anthracycline, adriamycin and cyclophosphamide (A/C), and 5-fluorouracil, adriamycin and cyclophosphamide (FAC). At this time, only $21.5 \%$ of the patients have presented with recurrence, and $18.1 \%$ present with deletion of the TOP $2 \alpha$ gene, which has been reported to be associated with resistance to anthracyclines (10-13). Furthermore, $18.1 \%$ of patients had TOP $2 \alpha$ overexpression, which is considered to be a predictive factor for drug sensitivity (10-13), and $27.2 \%$ had mutations in the $p 53$ gene, which are associated with poor response to anthracycline treatment $(7,23,31)$.

Finally, using MCA, we identified three groups that defined the present study population. The first group comprised TNBC patients presenting with $p 53$ mutations, p53 protein overexpression, and TOP $2 \alpha$ amplification. This group meets the characteristics from previous studies describing genetic alterations of the $p 53$ gene, or its protein overexpression, in TNBC patients. The second group comprised non-TNBC patients demonstrating $p 53$ gene deletions, underexpression of the p53 protein, and an unaltered TOP $2 \alpha$ gene, but overexpression of the TOP $2 \alpha$ protein and SBR histological grade II. This group is composed of patients with $\mathrm{BC}$ presenting a 65-bp deletion in the $p 53$ gene, thus explaining its protein underexpression. Conversely, p53 mutants could induce TOP $2 \alpha$ expression; however, we did not observe any correlation between $p 53$ point mutations (overexpression of p53) and TOP $2 \alpha$ protein overexpression (data not shown), suggesting that mechanisms other than p53 mutations are able to induce or regulate TOP $2 \alpha$ expression $(32,33)$. The third group included both non-TNBC and TNBC patients carrying a deletion in the TOP $2 \alpha$ gene and with baseline expression of the TOP $2 \alpha$ and p53 proteins. This analysis allowed us to identify well-defined groups of patients associated with the characteristics analysed who exhibited tumour heterogeneity. Furthermore, through this analysis, we 
identified a specific group containing TNBC patients and p53 overexpression, both characteristics that are associated with poor prognosis. Similarly, MAC has been used to associate clinicopathological features of patients with cancer (34). The limitations of the present study included a short follow-up time period for the patients, insufficient DNA material for identifying deletions in all samples with genetic alterations of the p53 gene, and only two schemes of available adjuvant chemotherapy (with or without anthracyclines) for comparison. It is necessary to carry out studies with a larger sample size to validate our results.

The present study population, is characterized by a high frequency of TNBC cases found mainly among the younger patients exhibiting SBR grade III, p53 gene mutations, and protein overexpression. P53 overexpression was associated with a lower survival in patients with $\mathrm{BC}$, suggesting that it is a factor for poor prognosis in our population.

\section{Acknowledgements}

Este estudio representa parte de los requisitos para obtener el grado a Doctor de Jisela Dimas González estudiante del Programa de Doctorado en Ciencias Biomédicas de la Universidad Nacional Autónoma de México (UNAM). JDG agradece el apoyo de CONACYT (no. Becario 175068). The authors wish to thank Enrique Garcia Villa (CINVESTAV-1PN) and Rubén Arturo Cortés González (INSP) for their technical assistance, and the Red Temática Farmoquímicos (CONACYT, \#271520) for help in to carry out the English language editing of the present study. This study was supported by grants from CONACyT (\#168896) and (\#261875) to J. Díaz-Chávez.

\section{References}

1. Olivier M, Langerød A, Carrieri P, Bergh J, Klaar S, Eyfjord J Theillet $\mathrm{C}$, Rodriguez $\mathrm{C}$, Lidereau $\mathrm{R}$, Bièche $\mathrm{I}$, et al: The clinical value of somatic TP53 gene mutations in 1,794 patients with breast cancer. Clin Cancer Res 12: 1157-1167, 2006.

2. Olivier M, Hollstein M and Hainaut P: TP53 mutations in human cancers: Origins, consequences, and clinical use. Cold Spring Harb Perspect Biol 2: a001008, 2010.

3. Banerji S, Cibulskis K, Rangel-Escareno C, Brown KK, Carter SL, Frederick AM, Lawrence MS, Sivachenko AY, Sougnez C, Zou L, et al: Sequence analysis of mutations and translocations across breast cancer subtypes. Nature 486: 405-409, 2012.

4. Fountzilas G, Giannoulatou E, Alexopoulou Z, Zagouri F, Timotheadou E, Papadopoulou K, Lakis S, Bobos M, Poulios C, Sotiropoulou M, et al: TP53 mutations and protein immunopositivity may predict for poor outcome but also for trastuzumab benefit in patients with early breast cancer treated in the adjuvant setting. Oncotarget 7: 32731-32753, 2016.

5. Bieging KT, Mello SS and Attardi LD: Unravelling mechanisms of p53-mediated tumour suppression. Nat Rev Cancer 14: 359-370, 2014.

6. Cho Y, Gorina S, Jeffrey PD and Pavletich NP: Crystal structure of a p53 tumor suppressor-DNA complex: Understanding tumorigenic mutations. Science 265: 346-355, 1994.

7. Fernández-Cuesta L, Oakman C, Falagan-Lotsch P, Smoth KS Quinaux E, Buyse M, Dolci MS, Azambuja ED, Hainaut P, Dell'órto P, et al: Prognostic and predictive value of TP53 mutations in node-positive breast cancer patients treated with anthracycline- or anthracycline/taxane-based adjuvant therapy: Results from the BIG 02-98 phase III trial. Breast Cancer 14: R70, 2012.

8. Wang Q, Zambetti GP and Suttle DP: Inhibition of DNA topoisomerase II $\alpha$ gene expression by the p53 tumor suppressor. Mol Cell Biol 17: 389-397, 1997.

9. Joshi AA, Wu Z, Reed RF and Suttle DP: Nuclear factor-Y binding to the topoisomerase IIalpha promoter is inhibited by both the p53 tumor suppressor and anticancer drugs. Mol Pharmacol 63: 359-367, 2003.
10. Bartlett JM, Munro AF, Dunn JA, McConkey C, Jordan S, Twelves CJ, Cameron DA, Thomas J, Campbell FM, Rea DW, et al: Predictive markers of anthracycline benefit: A prospectively planned analysis of the UK National Epirubicin Adjuvant Trial (NEAT/BR9601). Lancet Oncol 11: 266-274, 2010.

11. Brase JC, Schmidt M, Fischbach T, Sültmann H, Bojar H, Koelbl H, Hellwig B, Rahnenführer J, Hengstler JG and Gehrmann MC: ERBB2 and TOP2A in breast cancer: A comprehensive analysis of gene amplification, RNA levels, and protein expression and their influence on prognosis and prediction. Clin Cancer Res 16: 2391-2401, 2010.

12. Di Leo A, Desmedt C, Bartlett JM, Piette F, Ejlertsen B, Pritchard KI, Larsimont D, Poole C, Isola J, Earl H, et al; HER2/TOP2A Meta-analysis Study Group: HER2 and TOP2A as predictive markers for anthracycline-containing chemotherapy regimens as adjuvant treatment of breast cancer: A meta-analysis of individual patient data. Lancet Oncol 12: 1134-1142, 2011.

13. Won HS, Lee KE, Sung SH, Choi MY, Jo JY, Nam EM, Mun YC, Seong CM and Lee SN: Topoisomerase II alpha and microtubule-associated protein-tau as a predictive marker in axillary lymph node positive breast cancer. Tumori 100: 80-86, 2014.

14. Györffy B, Lanczky A, Eklund AC, Denkert C, Budczies J, Li Q and Szallasi Z: An online survival analysis tool to rapidly assess the effect of 22,277 genes on breast cancer prognosis using microarray data of 1,809 patients. Breast Cancer Res Treat 123: 725-731, 2010.

15. Qiao JH, Jiao DC, Lu ZD, Yang S and Liu ZZ: Clinical significance of topoisomerase $2 \mathrm{~A}$ expression and gene change in operable invasive breast cancer. Tumour Biol 36: 6833-6838, 2015.

16. Hill MO: Correspondence analysis: A neglected multivariate method. Appl Stat 3: 340-354, 1974.

17. Kim JY, Park K, Jung HH, Lee E, Cho EY, Lee KH, Bae SY, Lee SK, Kim SW, Lee JE, et al: Association between mutation and expression of $T P_{53}$ as a potential prognostic marker of triple-negative breast cancer. Cancer Res Treat 48: 1338-1350, 2016.

18. Lara-Medina F, Pérez-Sánchez V, Saavedra-Pérez D, Blake-Cerda M, Arce C, Motola-Kuba D, Villarreal-Garza C, González-Angulo AM, Bargalló E, Aguilar JL, et al: Triple-negative breast cancer in Hispanic patients: High prevalence, poor prognosis, and association with menopausal status, body mass index, and parity. Cancer 117: 3658-3669, 2011.

19. Liedtke C, Mazouni C, Hess KR, André F, Tordai A, Mejia JA, Symmans WF, Gonzalez-Angulo AM, Hennessy B, Green M, et al: Response to neoadjuvant therapy and long-term survival in patients with triple-negative breast cancer. J Clin Oncol 26: 1275-1281, 2008.

20. Banegas MP, Tao L, Altekruse S, Anderson WF, John EM, Clarke CA and Gomez SL: Heterogeneity of breast cancer subtypes and survival among Hispanic women with invasive breast cancer in California. Breast Cancer Res Treat 144: 625-634, 2014.

21. Fountzilas G, Christodoulou C, Bobos M, Kotoula V, Eleftheraki AG, Xanthakis I, Batistatou A, Pentheroudakis G, Xiros N, Papaspirou I, et al: Topoisomerase II alpha gene amplification is a favorable prognostic factor in patients with HER2-positive metastatic breast cancer treated with trastuzumab. J Transl Med 10: 212, 2012.

22. Hua W, Sa KD, Zhang X, Jia LT, Zhao J, Yang AG, Zhang R, Fan $\mathrm{J}$ and Bian K: MicroRNA-139 suppresses proliferation in luminal type breast cancer cells by targeting Topoisomerase II alpha. Biochem Biophys Res Commun 463: 1077-1083, 2015.

23. Dobes P, Podhorec J, Coufal O, Jureckova A, Petrakova K, Vojtesek B and Hrstka R: Influence of mutation type on prognostic and predictive values of TP53 status in primary breast cancer patients. Oncol Rep 32: 1695-1702, 2014.

24. Bazrafshani MR, Nowshadi PA, Shirian S, Daneshbod Y, Nabipour F, Mokhtari M, Hosseini F, Dehghan S, Saeedzadeh A and Mosayebi Z: Deletion/duplication mutation screening of TP53 gene in patients with transitional cell carcinoma of urinary bladder using multiplex ligation-dependent probe amplification. Cancer Med 5: 145-152, 2016.

25. Delfau-Larue MH, Klapper W, Berger F, Jardin F, Briere J, Salles G, Casasnovas O, Feugier P, Haioun C, Ribrag V, et al; European Mantle Cell Lymphoma Network: High-dose cytarabine does not overcome the adverse prognostic value of $C D K N 2 A$ and TP53 deletions in mantle cell lymphoma. Blood 126: 604-611, 2015.

26. Dufour A, Palermo G, Zellmeier E, Mellert G, DuchateauNguyen G, Schneider S, Benthaus T, Kakadia PM, Spiekermann K, Hiddemann W, et al: Inactivation of TP53 correlates with disease progression and low miR-34a expression in previously treated chronic lymphocytic leukemia patients. Blood 121: 3650-3657, 2013. 
27. Millis SZ, Gatalica Z, Winkler J, Vranic S, Kimbrough J, Reddy S and O'Shaughnessy JA: Predictive biomarker profiling of $>6000$ breast cancer patients shows heterogeneity in TNBC, with treatment implications. Clin Breast Cancer 15: 473-481.e3, 2015.

28. Yang P, Du CW, Kwan M, Liang SX and Zhang GJ: The impact of p53 in predicting clinical outcome of breast cancer patients with visceral metastasis. Sci Rep 3: 2246, 2013.

29. Ren J, Chen QC, Jin F, Wu HZ, He M, Zhao L, Yu ZJ, Yao WF, Mi XY, Wang EH, et al: Overexpression of Rsf-1 correlates with pathological type, p53 status and survival in primary breast cancer. Int J Clin Exp Pathol 7: 5595-5608, 2014.

30. Maeda T, Nakanishi Y, Hirotani Y, Fuchinoue F, Enomoto K, Sakurai K, Amano S and Nemoto N: Immunohistochemical co-expression status of cytokeratin $5 / 6$, androgen receptor, and p53 as prognostic factors of adjuvant chemotherapy for triple negative breast cancer. Med Mol Morphol 49: 11-21, 2016.
31. Lehmann BD, Ding Y, Viox DJ, Jiang M, Zheng Y, Liao W, Chen X, Xiang W and Yi Y: Evaluation of public cancer datasets and signatures identifies TP53 mutant signatures with robust prognostic and predictive value. BMC Cancer 15: 179, 2015.

32. Srikantan S, Abdelmohsen K, Lee EK, Tominaga K, Subaran SS, Kuwano Y, Kulshrestha R, Panchakshari R, Kim HH, Yang X, et al: Translational control of TOP2A influences doxorubicin efficacy. Mol Cell Biol 31: 3790-3801, 2011

33. Tamaichi H, Sato M, Porter AC, Shimizu T, Mizutani S and Takagi M: Ataxia telangiectasia mutated-dependent regulation of topoisomerase II alpha expression and sensitivity to topoisomerase II inhibitor. Cancer Sci 104: 178-184, 2013.

34. Rodriguez-Lara V, Peña-Mirabal E, Baez-Saldaña R, Esparza-Silva AL, García-Zepeda E, Cerbon Cervantes MA, Diaz D and Fortoul TI: Estrogen receptor beta and CXCR4/CXCL12 expression: Differences by sex and hormonal status in lung adenocarcinoma. Arch Med Res 45: 158-169, 2014. 